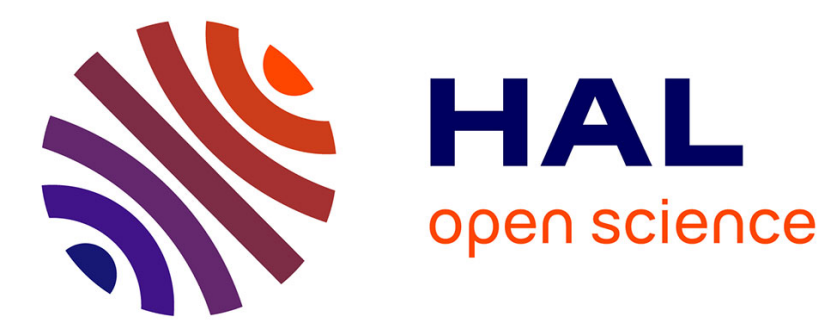

\title{
Monodisperse droplet heating and evaporation: Experimental study and modelling
}

Christophe Maqua, Guillaume Castanet, Frederic Grisch, Fabrice Lemoine, T Kristyadi, Sergei Sazhin

\section{- To cite this version:}

Christophe Maqua, Guillaume Castanet, Frederic Grisch, Fabrice Lemoine, T Kristyadi, et al.. Monodisperse droplet heating and evaporation: Experimental study and modelling. International Journal of Heat and Mass Transfer, 2008, 51, pp.3932 - 3945. 10.1016/j.ijheatmasstransfer.2007.12.011 . hal-01570367

\section{HAL Id: hal-01570367 \\ https://hal.univ-lorraine.fr/hal-01570367}

Submitted on 29 Jul 2017

HAL is a multi-disciplinary open access archive for the deposit and dissemination of scientific research documents, whether they are published or not. The documents may come from teaching and research institutions in France or abroad, or from public or private research centers.
L'archive ouverte pluridisciplinaire HAL, est destinée au dépôt et à la diffusion de documents scientifiques de niveau recherche, publiés ou non, émanant des établissements d'enseignement et de recherche français ou étrangers, des laboratoires publics ou privés. 


\title{
Monodisperse droplet heating and evaporation: Experimental study and modelling
}

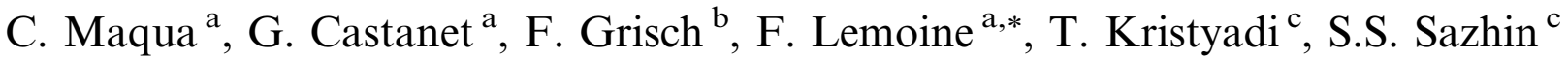 \\ ${ }^{a}$ LEMTA, Nancy-Université, CNRS UMR 7563, 2, Avenue de la Forêt de Haye, BP 160, 54504 Vandouvre-lès-Nancy, France \\ ${ }^{\mathrm{b}}$ ONERA, Fort de Palaiseau, 91761 Palaiseau Cedex, France \\ ${ }^{\mathrm{c}}$ School of Environment and Technology, Faculty of Science and Engineering, University of Brighton, Brighton, BN2 4GJ, UK
}

\begin{abstract}
Results of experimental studies and the modelling of heating and evaporation of monodisperse ethanol and acetone droplets in two regimes are presented. Firstly, pure heating and evaporation of droplets in a flow of air of prescribed temperature are considered. Secondly, droplet heating and evaporation in a flame produced by previously injected combusting droplets are studied. The phase Doppler anemometry technique is used for droplet velocity and size measurements. Two-colour laser induced fluorescence thermometry is used to estimate droplet temperatures. The experiments have been performed for various distances between droplets and various initial droplet radii and velocities. The experimental data have been compared with the results of modelling, based on given gas temperatures, measured by coherent anti-stokes Raman spectroscopy, and Nusselt and Sherwood numbers calculated using measured values of droplet relative velocities. When estimating the latter numbers the finite distance between droplets was taken into account. The model is based on the assumption that droplets are spherically symmetrical, but takes into account the radial distribution of temperature inside droplets. It is pointed out that for relatively small droplets (initial radii about $65 \mu \mathrm{m}$ ) the experimentally measured droplet temperatures are close to the predicted average droplet temperatures, while for larger droplets (initial radii about $120 \mu \mathrm{m}$ ) the experimentally measured droplet temperatures are close to the temperatures predicted at the centre of the droplets.
\end{abstract}

\section{Introduction}

The importance of sprays in various engineering and environmental applications is well known [1]. Heating, evaporation and combustion models of isolated droplets are widely available in the literature ([1-4]). Although there are a number of publications where these processes in droplet clusters were studied (e.g. $[5,6])$, the present understanding of droplet-to-droplet interactions is still limited. These processes have been mainly studied based on simplified configurations. From the experimental point of view, it is very difficult to work on full scale facilities that do not offer control of injection and environmental parameters over a wide range. Also, in the analysis of spray measure-

\footnotetext{
* Corresponding author.

E-mail address: fabrice.lemoine@ensem.inpl-nancy.fr (F. Lemoine).
}

ments it is difficult, in fact almost impossible, to separate the relative influences of the environmental and injection parameters. These problems are not encountered for linearly streamed monodisperse droplets. The size, velocity, temperature and spacing of the droplets can be adjusted separately at the injection, where the ambient conditions can be controlled [7]. This kind of droplet stream is therefore an interesting tool for investigating droplet-to-droplet interactions and it has already been used in previous numerical and experimental studies. Sangiovanni and Kesten [8] were perhaps the first to investigate the effects of droplet interaction on the ignition time for droplet streams injected into a hot gas environment. They noticed that a closer spacing of the droplets enhances the strength of the heat and mass diffusion from the flame region. Sangiovanni and Labowsky [9] reported measurements of the droplet lifetime under similar conditions. They found that the 


\begin{tabular}{|c|c|c|c|}
\hline \multicolumn{4}{|c|}{ Nomenclature } \\
\hline$B_{\mathrm{M}}$ & Spalding mass transfer number & $z$ & vertical position \\
\hline$B_{\mathrm{T}}$ & Spalding heat transfer number & & \\
\hline$c$ & specific heat capacity & \multicolumn{2}{|c|}{ Greek symbols } \\
\hline$C$ & distance parameter introduced in Eq. (9) & $\eta$ & parameter introduced in Eq. (9) \\
\hline$D$ & molecular diffusivity or nozzle diameter & $\kappa_{0}$ & parameter introduced in Eq. (4) \\
\hline$F$ & function introduced in Eqs. (7) and (8) & $\lambda$ & wavelength \\
\hline$h$ & convection heat coefficient & $\lambda_{\mathrm{n}}$ & eigenvalues introduced in Eq. (4 \\
\hline$h_{0}$ & parameter introduced in Eq. (4) & $\mu$ & dynamic viscosity \\
\hline$k$ & thermal conductivity & $\rho$ & density \\
\hline K & thermal diffusivity & $\chi$ & $k_{\mathrm{efff}} / k_{1}$ \\
\hline$L$ & specific heat of evaporation & $\omega$ & angular frequency \\
\hline$m$ & mass & & \\
\hline$N u$ & Nusselt number & \multicolumn{2}{|c|}{ Subscripts } \\
\hline$p_{\mathrm{n}}$ & parameter introduced in Eq. (4) & av & average \\
\hline$P e$ & Peclet number & AS & anti-Stokes \\
\hline $\operatorname{Pr}$ & Prandtl number & $\mathrm{c}$ & centre \\
\hline$q_{\mathrm{n}}$ & parameter introduced in Eq. (4) & $\mathrm{d}$ & droplet \\
\hline $\operatorname{Re}$ & Reynolds number & eff & effective \\
\hline$R$ & distance from the centre of the droplet & $\mathrm{g}$ & gas \\
\hline$S c$ & Schmidt number & 1 & liquid \\
\hline$S h$ & Sherwood number & $\mathrm{P}$ & pump \\
\hline$t$ & time & $\mathrm{s}$ & surface \\
\hline$T$ & temperature & $\mathrm{S}$ & Stokes \\
\hline$v$ & velocity & $\mathrm{v}$ & vapour \\
\hline$V_{\mathrm{n}}$ & eigenfunction & 0 & initial \\
\hline
\end{tabular}

classical " $\mathrm{D}^{2}$-Law" is not strictly applicable to interacting droplets due to the transient nature of that interaction. Brzustowski et al. [10] studied the combustion of two motionless droplets of arbitrary size by solving the Laplace equation for vapour concentration. They quantified the reduction in the burning rate when droplets approach each other almost to come into contact. Labowsky [11] and Marberry et al. [12] used the point sources method to determine the burning rates of stagnant droplets in finite arrays containing up to eight symmetrically arranged monodisperse droplets. Later, the effect of droplet motion was taken into account by Chiang and Sirignano $[13,14]$ who performed a comprehensive numerical study of two and three evaporating droplets moving together. Their computation included: the effects of variable thermophysical properties, transient heating and internal circulation in the liquid phase, boundary layer blowing, moving interface due to surface regression, and the relative motion between the droplets.

More recently, two experimental studies of droplet interactions in monodisperse streams were reported by Castanet et al. $[15,16]$. The two-colour laser induced fluorescence technique was used by the authors to measure droplet temperature. This technique was combined with the measurement of droplet sizes using either phase Doppler anemometry or interferometry using light scattered by the droplets in forward direction. Knowledge of the size, velocity and temperature of the droplets enabled the authors to estimate the heat fluxes acting on the evaporating droplets. Results were obtained for a relatively large set of data corresponding to droplets moving into a flame or within the thermal boundary layer of a vertical heated plate. The distance parameter, defined as the droplet spacing divided by the droplet diameter, was increased up to almost 20 by removing electrically charged droplets with an applied electrostatic field. For the case of combusting droplets, the authors suggested a correction factor that should be applied to the Nusselt and Sherwood numbers for isolated droplets to take onto account interaction between droplets. This correction is a function of the distance parameter. For distance parameters larger than 9, the interaction effects were shown to be negligible.

In the present paper, the results of further experimental and numerical studies of the dynamic heating and evaporation of fuel droplet arrays are reported. The measurements have been performed in two different conditions: heating and evaporation of droplets in a hot air flow of given temperature and in a flame. Ethanol and acetone fuels were chosen for the experimental study since these fuels have rather different volatilities. The spectroscopic properties of the mixture of ethanol and acetone were characterized in a previous study [17]. The space-averaged temperature 
of the droplets was measured using the two-colour laser induced fluorescence technique. For meaningful comparisons between simulations and measurements, the comparative sizes of the droplets and the measurement volume were taken into account. When the droplets were larger than the probe volume of the optics, the probe was unable to detect the whole of the fluorescence signal produced by a single droplet; this introduced a bias to the calculation of average temperature. In the first set of experiments, the ambient gas temperature was measured by a K-type thermocouple. In the case of heating and evaporation of fuel droplets in a flame produced by previously injected droplets, this parameter is deduced from measurements performed by CARS thermometry (coherent anti-stokes Raman scattering). This technique, which is based on pioneering investigations by Druet and Taran [18], has received considerable attention from those studying combustion during the last two decades.

The model used for the analysis of experimental data is essentially based on the one originally developed by Abramzon and Sirignano [2] and further adapted for numerical simulation of droplet heating and evaporation, taking into account the effect of thermal radiation in [1921]. The recirculation inside droplets is considered via the introduction of the effective thermal conductivity of droplets (effective thermal conductivity model). In the gas phase, the model takes into account the effect of finite thickness of the thermal boundary layer around droplets. The radiative heating of droplets is calculated taking into account their semi-transparency. This model has been further developed to capture the effect of the finite distance parameter, introduced earlier in this section.

The experimental set-up is described in Section 2. In Section 3, the numerical model used in the analysis is discussed. In Section 4, experimental and numerical results are compared and discussed. The main results of the paper are summarised in Section 5.

\section{Experimental set-up}

\subsection{The monodisperse droplet stream}

Linear monodisperse droplet streams are generated by Rayleigh disintegration of a liquid jet undergoing vibrations generated in a piezoelectric ceramic (Fig. 1). The voltage applied to the piezoceramic is a square wave, the amplitude of which determines the position of the breakup zone for a given fuel at a given temperature. The fuel is pre-heated in the injector by means of externally heated circulating water. The temperature of the fuel is measured exactly at the injection point with a $\mathrm{K}$ type thermocouple. For specific frequencies of forced mechanical vibration, the liquid jet breaks up into equally spaced and monosized droplets [7]. By adjusting the liquid flow rate and the piezoceramic frequency, it is possible to increase the droplet spacing up to about 6 times the droplet diameter. This, however, is accompanied by a modification of droplet sizes. A device, enabling the electrostatic deviation of the droplets, has been used to increase further the droplet spacing without changing the droplet diameter. As described by Castanet et al. [15], this device, called a deviator, is mounted at the injector exit. When droplets pass through the ring (positioned just at the break-up location of the cylindrical jet), they are negatively charged by electrical impulses transmitted by the ring (Fig. 2). The frequency of the impulses can be controlled in such a way that only a fraction of the droplets acquire charges. Afterwards, a high intensity electrostatic field is applied to the droplets when they enter the gap between the two electrodes at constant voltage. The charged droplets are deviated from their vertical trajectory and picked up, whereas the remaining droplets form a stream with increased spacing.

Two liquids were tested: ethanol and acetone, which have significantly different volatilities. To investigate pure evaporation, droplets are injected in a hot co-flowing air

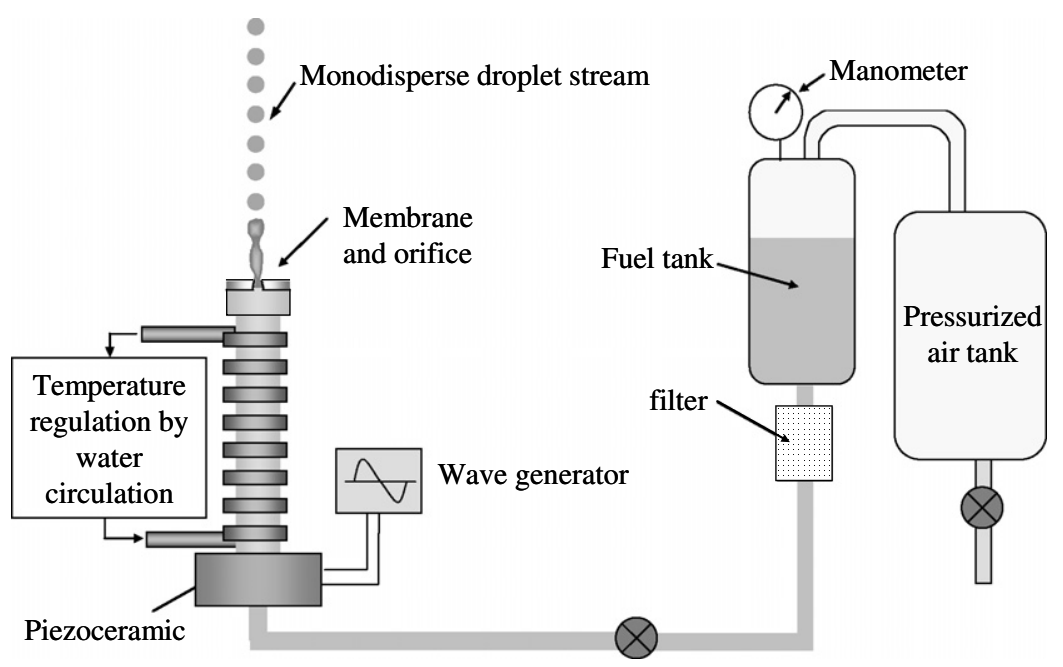

Fig. 1. Generation of a monodispersed stream. 


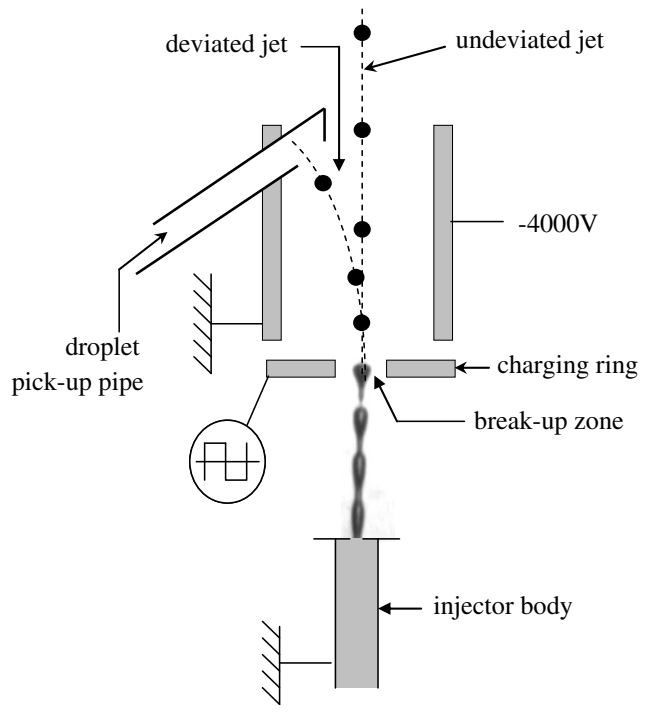

Fig. 2. Electrostatic deviation of the droplets.

stream, released from two electrical heaters, arranged symmetrically relative to the droplet streaming axis [22]. The air velocity, as measured by laser Doppler anemometry (LDA), was about $2 \mathrm{~m} / \mathrm{s}$ in the vicinity of the droplet injection point (Fig. 3c). The air is premixed with small particles released by a smoke generator. The air temperature field, measured by a thermocouple, decreased from $550{ }^{\circ} \mathrm{C}$ at the injection point to about $100^{\circ} \mathrm{C}$ at $z=60 \mathrm{~mm}$ (Fig. 3a and b).

To study droplet heating and evaporation in a flame, an electrically heated coil was positioned just after the breakup zone of the liquid jet, and a laminar flame with a column shape was obtained [16]. The temperature field within the flame was characterized by CARS. An outline of the way in which these measurements were taken is presented in the following section.

\subsection{Measurement of the gas temperature in the flame by $N_{2}$ broadband CARS}

A detailed report of CARS theory, including the derivation of expressions for the signal intensity and description of numerous technical approaches in practical measurement systems is described in numerous textbooks and papers (e.g. $[23,24])$. In what follows, a brief overview of this technique is given. CARS is a four wave parametric process in which three waves, two at the pump frequency $\left(\omega_{\mathrm{P}}\right)$ and one at the Stokes frequency $\left(\omega_{\mathrm{S}}\right)$, are focused on the measurement point in the sample to produce a new coherent beam at the anti-Stokes frequency $\left(\omega_{\mathrm{AS}}=2 \omega_{\mathrm{P}}-\omega_{\mathrm{S}}\right)$. The strength of the interaction depends on the nonlinear third-order susceptibility of the medium, which is greatly enhanced when the frequency difference $\left(\omega_{\mathrm{P}}-\omega_{\mathrm{S}}\right)$ matches a Raman active vibrational resonance in the medium. The nonlinear susceptibility is density and temperature-dependent providing the basis for diagnostics. Measurements of medium properties are performed from the shape of the spectral signatures and/or intensity of the CARS radiation. Temperature information is based on the fact that the intensity distributions of the transitions in a CARS spectrum are relative to the populations of the rotational and vibrational levels of the studied molecules and consequently, the thermodynamic temperature of the system. The CARS system uses the second harmonic

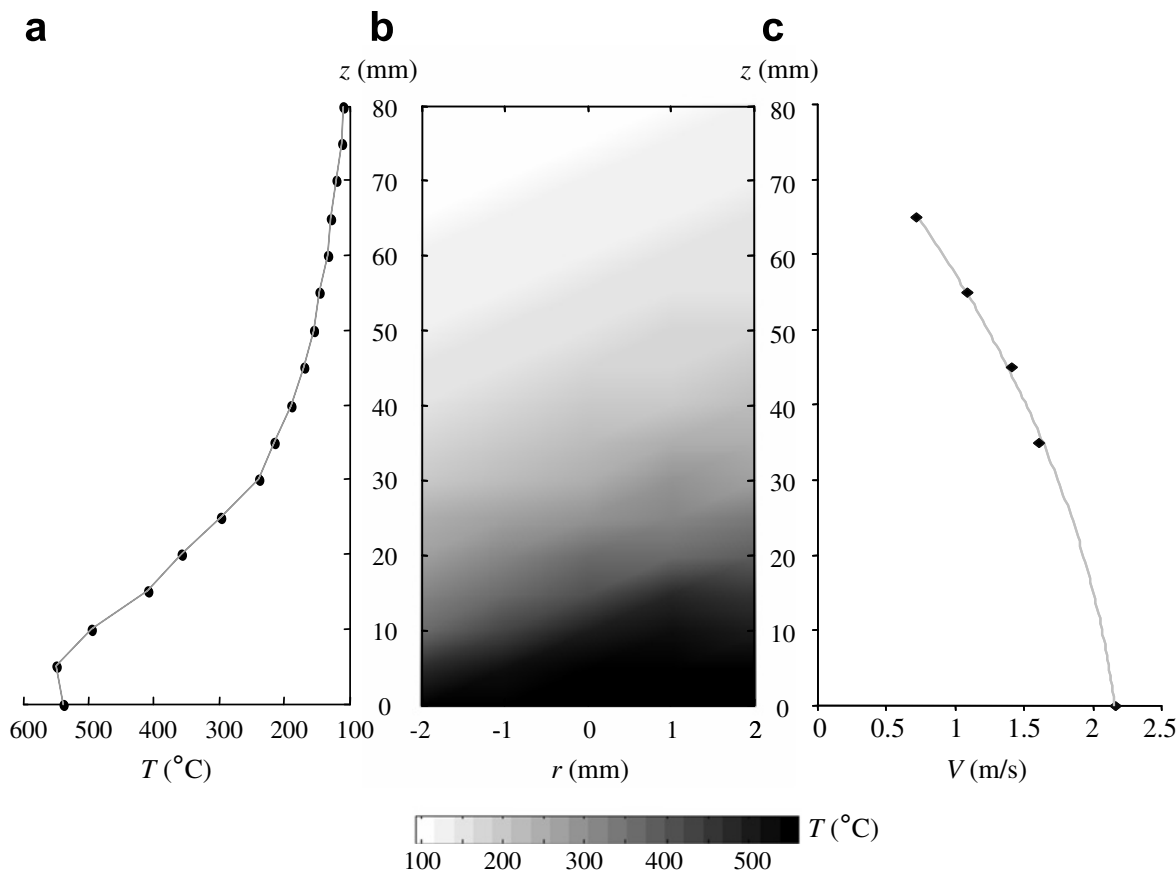

Fig. 3. Temperature and air velocity in the hot air plume (a) profile of the temperature along the $z$-axis at $r=0$, (b) spatial distribution of the temperature within the air plume and (c) profile of the gas velocity along the $z$-axis at $r=0$. 
$(532 \mathrm{~nm})$ of a pulsed Nd:YAG laser as its primary laser source. Part of the 532-nm light pumps a Rhodamine 6G dye laser oscillator to generate a broadband $\left(150 \mathrm{~cm}^{-1}\right)$ Stokes laser beam peaked at $607 \mathrm{~nm}$. The peak of the dye laser output is concentration tuned to probe the N2 Q-branch. All the laser beams are then focused on the monodisperse droplet flame with a planar BOXCARS arrangement by means of a single $160 \mathrm{~mm}$-focal-length achromat lens yielding a $0.5 \mathrm{~mm}$-long and $30 \mu \mathrm{m}$-diameter probe volume. This is sufficiently small compared to the droplet diameter $(\sim 200 \mu \mathrm{m})$. The crossing frequency of the droplets is monitored by passing a He:Ne laser through the droplet stream and by detecting the variation in the signal of the beam using a PIN photodiode. The phase angles, on which single-shot measurements are performed, are obtained by comparing the delay between the laser pulse and the periodic signal generated by the PIN photodiode using a chronometer (Hewlett Packard, 5345A). For each spatial location in the flame, 400 single-shot $\mathrm{N}_{2}$ CARS spectra were recorded in time for temperature determination. For each single-shot measurement, the experimental CARS spectrum was fitted, using least-square minimisation routine, to theoretical spectra simulated using the CARS modelling approach described in [24]. In the present study, the collisional line-broadening parameters used to simulate the $\mathrm{N}_{2}$ spectra in the whole temperature range were taken from the modified energy gap law of Bonamy et al. [25]. Typically, the accuracy of temperature measurements, which were found to be sensitive to collisional narrowing and nitrogen line-widths, is equal to $5 \%$ at room temperature $( \pm 15 \mathrm{~K})$, and then decreases progressively to $2 \%$ at $1700 \mathrm{~K}( \pm 30 \mathrm{~K})$. For each spatial location, the temperature time-profile between droplets is flat so that it becomes possible to determine an average temperature from the series of single-shot measurements. Fig. 4 shows a typical radial profile of the mean temperatures within a flame surrounding pure ethanol droplets. The flame front can be

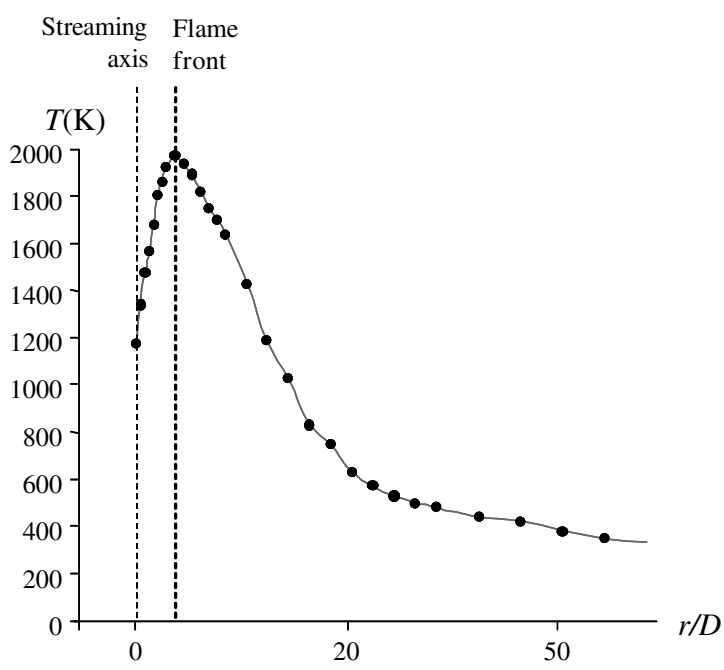

Fig. 4. Radial profile of the gas temperature in the flame. clearly seen since it corresponds to a maximum of about $2000 \mathrm{~K}$.

When dealing with combusting droplets, the ambient temperature, used to estimate the convective heat transfers, is taken on the flame axis where the moving droplets are mainly located. The effects of the distance parameter on the flame temperature were investigated in detail with the help of this technique. Data referring to four droplet streams with different droplet spacing are shown in Fig. 5 for a time $3.2 \mathrm{~ms}$ after droplets left the injector and for droplet diameters of about $200 \mu \mathrm{m}$. It can be seen that the temperature on the flame axis and at the flame front increases slightly with the initial distance parameter.

\subsection{Velocity and size measurements}

Phase Doppler anemometry (PDA) in the refraction mode was used to measure droplet velocities and diameters at various distances from the injector. The main problem with the size measurements arises from trajectory ambiguity. When the droplet size is of the order or larger than the laser beam, the Doppler signal may be altered by unwanted scattering modes which may lead to error in the measurements. The risk of error is very high when the droplets are large compared to the width of the laser beam in the probe volume. To reduce the trajectory effects as much as possible, the position of the stream axis in the probe volume can be adjusted so that the contribution of the refractive mode is strengthened compared to the reflection mode in the direction of the receiving optics. A calibration of the PDA is required to achieve accurate size measurements. Both the positioning of the droplet streams and the calibration process were performed as described by Castanet et al. [16]. The discrepancy was about $1 \mu \mathrm{m}$ for droplet diameters around $100 \mu \mathrm{m}$. The droplet velocity was measured simultaneously by processing the Doppler frequency of the bursts at $\pm 1 \%$. Size measurements were performed only

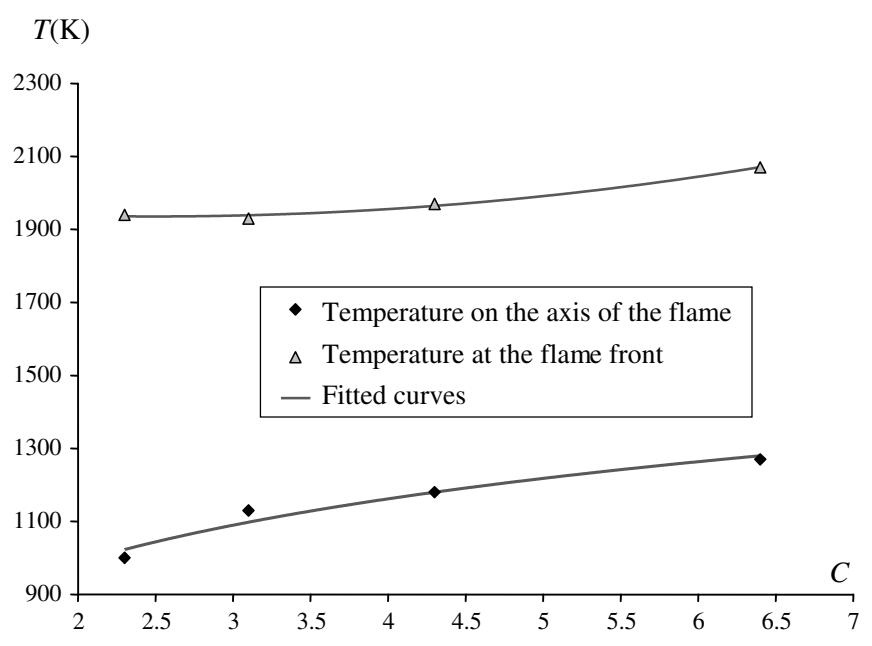

Fig. 5. Temperature in the flame as a function of the distance parameter. 
for combusting droplets, since the size reduction of droplets evaporating within the hot air plume were too small to be captured with sufficient accuracy by this technique. In this case, the initial droplet diameter was evaluated by a simple measurement of the fuel flowrate, the droplet injection frequency being known. The accuracy of this measurement was within $\pm 0.5 \mu \mathrm{m}$.

\subsection{Two-colour laser induced fluorescence thermometry}

Only an outline of the two-colour laser induced fluorescence technique is given in this section. Further technical details can be found in [26,27]. The fuel is seeded with a low concentration (a few $\mathrm{mg} / \mathrm{l}$ ) of rhodamine $\mathrm{B}$, which is an organic dye usually used as a fluorescent temperature sensor. Furthermore, the fluorescence of rhodamine B can be easily induced by the green line $(\lambda=514.5 \mathrm{~nm})$ of the argon ion laser. The technique requires two spectral bands of detection with highly different temperature sensitivities. The ratio of the fluorescence signal measured on the two spectral bands of detection appears to be only temperature-dependent and the dependencies on tracer concentration, probe volume dimensions, laser intensity and optical layout are removed [26]. If the probe volume is sufficiently large to provide a global excitation of the whole of the droplet and if the signal is averaged over the droplet's entire transit through the probe volume, a volume averaged droplet temperature can be obtained. The two crossing laser beams of the PDA system are also used to induce the fluorescence. The emitted photons are collected by a doublet located at $90^{\circ}$ to the incident beams and the optical signal is transmitted to an optical fibre. The incident laser light scattered by the droplets is removed by means of a high-pass optical filter to enable the collection of the fluorescence emission only. The remaining fluorescence is separated into the two spectral bands by means of interference filters. Finally, the photon flux is converted into an electrical signal by photomultiplier tubes.

The layout of this set-up, however, differs slightly depending on whether the experiment is focused on combusting or purely evaporating droplets. For combusting droplets, the PDA is used to perform size and velocity measurements. To avoid the ambiguity effects described in Section 2.3, a relatively large probe volume is formed, the dimensions of which are $4000 \mu \mathrm{m}$ along the laser beam axis and $243 \mu \mathrm{m}$ for the transverse dimension. In the case of the droplets evaporating in the hot air plume, the probe volume is smaller, $1200 \mu \mathrm{m}$ long and $150 \mu \mathrm{m}$ wide, since only the droplet velocity is measured. Regarding the collection optics, in the focus plane of the collection front lens, the image of the core of the optical fibre extends over roughly $200 \mu \mathrm{m}$ (this image, however, is slightly reduced in the presence of a droplet within the probe due to the refraction processes at the air-liquid interface).

Regions located near the droplet surface may make a rather limited contribution to the fluorescence signal depending on the optical arrangement, the size and the trajectory of the droplets. This comes essentially from the Gaussian distribution of the energy in the laser beams and the refraction at the droplet surface (see [17] for details). This effect can be safely ignored in the case of droplets significantly smaller than the probe volume. In the case of the purely evaporating droplets, this implies that, with regard to the sizes of the probe volume and droplets which evaporate, the measured temperature is more likely to be close to the temperature at the droplet centre instead of the volume averaged temperature, especially when the droplet diameter becomes larger than about $150 \mu \mathrm{m}$.

Note that droplet detection is based on the initial determination of the thresholds for each spectral band [26]. Each threshold is fixed at a high level, so that only the droplets well centred within the probe volume contribute to the temperature measurement. Multiple measurements carried out at the same location show a $\pm 1{ }^{\circ} \mathrm{C}$ dispersion of the averaged temperature.

\section{Model}

Assuming the spherical symmetry of the problem and ignoring the effect of thermal radiation, the general transient heat conduction equation inside a droplet is written as $[1,4]$ :

$\frac{\partial T}{\partial t}=\frac{K}{R^{2}} \frac{\partial}{\partial R}\left(R^{2} \frac{\partial T}{\partial R}\right)$,

where $K=k_{l} /\left(c_{l} \rho_{l}\right)$ is the liquid thermal diffusivity, $k_{l}$ is the liquid thermal conductivity assumed to be constant, $c_{l}$ and $\rho_{l}$ are the liquid specific heat capacity and density, respectively, $R$ is the distance from the centre of the droplet, $t$ is time, $T$ is the droplet temperature specified at the initial moment of time as $\left.T\right|_{t=0}=T_{0}(R)$.

The boundary condition at $R=0$ follows from the problem symmetry $\partial T /\left.\partial R\right|_{R=0}=0$. Assuming that the droplet is heated by convection from the surrounding gas, and cooled due to evaporation, the boundary condition at the droplet surface is written as:

$h\left(T_{\mathrm{g}}-T_{\mathrm{s}}\right)=-\rho_{l} L \frac{\mathrm{d} R_{\mathrm{d}}}{\mathrm{d} t}+\left.k_{l} \frac{\partial T}{\partial R}\right|_{R=R_{\mathrm{d}}}$,

where $R_{\mathrm{d}}$ is the droplet's radius, $T_{\mathrm{s}}$ is the droplet's surface temperature, $L$ is the specific heat of evaporation, $T_{\mathrm{g}}$ is the ambient gas temperature, $h$ is the convection heat transfer coefficient describing heat obtained by droplets from gas (due to heating of fuel vapour this heat is less than the heat lost by gas); effects of swelling are ignored at this stage.

The general analytical solution of Eq. (1), taking into account the changes in droplet radius due to evaporation, would be a difficult task. This is considerably simplified if we take into account that this solution will be used in the numerical analysis when the time step is small. In this case we can assume that the droplet radius is constant, but the 
effect of evaporation can be taken into account by replacing $T_{\mathrm{g}}$ with the effective temperature [19]:

$T_{\text {eff }}=T_{\mathrm{g}}+\rho_{l} L \frac{\mathrm{d} R_{\mathrm{d}}}{\mathrm{d} t} / h$.

This approximation can be justified by the large value of $L$. Its validity has been supported by direct comparison with the numerical solution of Eq. (1). In the case when the initial temperature inside the droplet is an arbitrary function of the distance from the droplet centre and the convection heat transfer coefficient is constant, the solution of Eq. (1), subject to the above-mentioned boundary and initial conditions, can be presented as [19]:

$$
\begin{aligned}
T= & T_{\text {eff }}+\frac{R_{\mathrm{d}}}{R} \sum_{n=1}^{\infty}\left\{\left[q_{n}-\frac{\sin \lambda_{n} \mu_{0}(0)}{\lambda_{n}^{2}\left\|V_{n}\right\|^{2}}\right] \exp \left(-\kappa_{0} \lambda_{n}^{2} t\right)\right. \\
& \left.-\frac{\sin \lambda_{n}}{\lambda_{n}^{2}\left\|V_{n}\right\|^{2}} \int_{0}^{t} \frac{\mathrm{d} \mu_{0}(\tau)}{\mathrm{d} \tau} \exp \left[-\kappa_{0} \lambda_{n}^{2}(t-\tau)\right] \mathrm{d} \tau\right\} \sin \left(\lambda_{n} R / R_{\mathrm{d}}\right)
\end{aligned}
$$

where $\mu_{0}=\frac{h T_{\text {eff }}(t) R_{\mathrm{d}}}{k_{l}}, q_{n}=\frac{1}{\left\|V_{n}\right\| R_{\mathrm{d}}^{2}} \int_{0}^{R_{\mathrm{d}}} R T_{0}(R) V_{n}(R) \mathrm{d} R$

$T_{0}(R)$ is the droplet initial temperature distribution, $\kappa_{0}=k_{l} /\left(c_{l} \rho_{l} R_{d}^{2}\right), \lambda_{n}$ are solutions of the equation:

$\lambda_{n} \cos \lambda_{n}+h_{0} \sin \lambda_{n}=0$,

$h_{0}=\frac{h R_{\mathrm{d}}}{k_{l}}-1, \quad\left\|V_{n}\right\|^{2}=0.5\left(1-\sin 2 \lambda_{n} / 2 \lambda_{n}\right)$,

$V_{n}=\sin \left(\lambda_{n} R / R_{\mathrm{d}}\right)$.

In our calculations it is assumed that initially the temperature inside droplets $T_{0}(R)$ is homogeneous (the dependence of temperature on $R$ is ignored). At the beginning of the following time steps the values of $T_{0}(R)$ are taken from the results of calculations at the previous time steps. Also, the analytical solution of Eq. (1) could be obtained in the case when $h$ is almost constant [19]. In the case of arbitrary $h$ the solution of Eq. (1) is reduced to the solution of the Volterra integral equation of the second kind [19]. These solutions, however, proved to be of limited practical importance for numerical analysis.

Solution (4) can be generalised to take into account the internal recirculation inside droplets. This is achieved by replacing the thermal conductivity of liquid $k_{l}$ with the so-called effective thermal conductivity $k_{\text {eff }}=\chi k_{l}$, where the coefficient $\chi$ varies from about 1 (at droplet Peclet number $<10$ ) to 2.72 (at droplet Peclet number $>500$ ) [2]. This model can predict the droplet average surface temperature, but not the distribution of temperature inside droplets. The former temperature controls droplet evaporation and is particularly important for practical applications. Also, this model is expected to predict accurately the droplet average temperature, but can lead to additional errors in estimating the temperature at the centre of the droplets. It is difficult to estimate these errors but they are expected to be comparable with the errors of experimental measurements.
Hence, the applicability of this model can be justified, and it is used in our analysis.

In the case of the infinitely large thermal conductivity of liquid fuels, solution (4) can be simplified to [19,28]:

$T=T_{\mathrm{s}}=T_{\text {eff }}+\left(T_{\mathrm{s} 0}-T_{\text {eff }}\right) \exp \left(-\frac{3 h t}{c_{l} \rho_{l} R_{\mathrm{d}}}\right)$,

where $T_{\mathrm{s} 0}$ is the initial droplet temperature. Droplet temperature does not depend on $R$ in this case. The model based on Eq. (5) (infinite liquid thermal conductivity model) is most widely used in CFD codes. Our analysis, however, will be based on Eq. (4), as it allows us to take into account the distribution of temperature inside droplets.

The values of $h$ used in Eqs. (2)-(5) are controlled by the conditions in the gas phase. Various approximations for $h$ are usually described in terms of the corresponding approximations for the Nusselt number $N u=2 h R_{\mathrm{d}} / k_{\mathrm{g}}$. Droplet heating, described in the previous section, is accompanied by droplet evaporation, described by the following equation:

$\frac{\mathrm{d} m_{\mathrm{d}}}{\mathrm{d} t}=-2 \pi D_{\mathrm{vg}} \rho_{\mathrm{total}} R_{\mathrm{d}} B_{\mathrm{M}} S h$,

where $m_{\mathrm{d}}$ is the mass of the droplet, $D_{\mathrm{vg}}$ is the diffusion coefficient of fuel vapour in air, $\rho_{\text {total }}$ is the total density of the mixture of fuel vapour and air, $S h$ is the Sherwood number, $B_{\mathrm{M}}$ is the Spalding mass transfer number. The difference between various gas models is essentially described in terms of different approximations for the Nusselt and Sherwood numbers. Based on [21], the following approximation for isolated droplets is used in our analysis:

$$
\begin{aligned}
N u_{\text {iso }}= & 2 \frac{\ln \left(1+B_{\mathrm{T}}\right)}{B_{\mathrm{T}}}\left(1+\left[\left(1+\operatorname{Re}_{\mathrm{d}} P r_{\mathrm{d}}\right)^{1 / 3}\right.\right. \\
& \left.\left.\times \max \left[1, \operatorname{Re}_{\mathrm{d}}^{0.077}\right]-1\right] /\left[2 F\left(B_{\mathrm{T}}\right)\right]\right) \\
S h_{\text {iso }}= & 2 \frac{\ln \left(1+B_{\mathrm{M}}\right)}{B_{\mathrm{M}}}\left(1+\left[\left(1+\operatorname{Re}_{\mathrm{d}} S c_{\mathrm{d}}\right)^{1 / 3}\right.\right. \\
& \left.\left.\max \left[1, \operatorname{Re}_{\mathrm{d}}^{0.077}\right]-1\right] /\left[2 F\left(B_{\mathrm{M}}\right)\right]\right),
\end{aligned}
$$

where $B_{\mathrm{T}}$ is the Spalding heat transfer number, $R e_{\mathrm{d}}, P r_{\mathrm{d}}$, $S c_{\mathrm{d}}$ are the Reynolds (based on droplet diameter), Prandtl and Schmidt numbers, respectively and $F$ is defined by:

$F\left(B_{\mathrm{T}, \mathrm{M}}\right)=\left(1+B_{\mathrm{T}, \mathrm{M}}\right)^{0.7} \frac{\ln \left(1+B_{\mathrm{T}, \mathrm{M}}\right)}{B_{\mathrm{T}, \mathrm{M}}}$.

In the case of droplet streams, Castanet et al. [16] suggested the following correction to take into account the finite distance parameter $C$ (ratio of the distance between droplets and their diameters),

$\frac{N u}{N u_{\text {iso }}}=\frac{S h}{S h_{\text {iso }}}=\eta(C)$,

where $\eta(C)=\tanh (0.36 C-0.82)$ and $C>3$.

To evaluate the Reynolds number $R e_{\mathrm{d}}$ in Eqs. (7) and (8), the droplet velocity relative to the gas is required. 
Although the droplet deceleration could have been modelled, the droplet velocity was fixed at its experimental value in the simulation. This choice enabled us to avoid errors due to the estimation of the droplet drag coefficients and to focus exclusively on heating and evaporation processes. All transport coefficients for air, alongside its density and specific heat capacity, were calculated in a similar way to [21]. The temperature dependencies of all physical properties of air were taken into account.

Eq. (1) and its solution (4) could be generalised to take into account the effect of radiative heating of semi-transparent fuel droplets [19]. The main obstacle in doing this, however, is that the spectra of ethanol and acetone are not known to us. To estimate the possible contribution of thermal radiation, the ethanol and acetone droplets were considered to have iso-octane radiative properties. It was shown that the predicted temperatures and pressures in the presence and absence of thermal radiation differ by not more than about $2 \%$ in most cases, even if the radiation temperature was assumed to be equal to the maximal temperature in the flame (this is true only when gas is totally transparent to thermal radiation). Since this error can be tolerated in our analysis, we believe that the effect of thermal radiation can be ignored as the first step in the modelling of the process.

Eqs. (4) and (6) have been used for calculating $T(R, t)$ and $R_{\mathrm{d}}(t)$ for arbitrary time-dependent gas temperature, using Eqs. (7)-(9) for Nusselt and Sherwood numbers. The calculations were performed over a time step which was so small that changes in gas temperature, velocity and droplet radius could be ignored in calculating the droplet temperature. In this case we can assume that $h(t)=$ const over this time step, which justifies the application of Eq. (4). At the first step we calculate $\dot{R}_{\mathrm{d}}(t=0)$ from Eq. (6) and $T_{\text {eff }}(t=0)$. Then the initial condition at $t=0$ allows us to calculate $T(R, t)$ at the end of the first time step $\left(T\left(t=t_{1}\right)\right)$ using Eq. (4). $\dot{R}_{\mathrm{d}}\left(t=t_{1}\right)$ is calculated based on Eq. (6) with the correction for swelling of the droplet. The same procedure is repeated for all the following time steps until the droplet is evaporated. The number of terms which need to be taken into account in the series in Eq. (4), depends on the timing of the start of droplet heating and the time when the value of droplet temperature is calculated. For parameters relevant to the Diesel engine environment, just three terms in the series were used with possible errors of not more than about $1 \%$. This approach was shown to be more CPU efficient and accurate than the one based on the numerical solution of Eq. (1) $[20]$.

For the comparison with experimental data the following temperatures were used: temperature at the surface of the droplet $T_{\mathrm{s}}$, temperature at the centre of the droplet $T_{\mathrm{c}}$, and the average droplet temperature:

$\bar{T}=\frac{3}{R_{\mathrm{d}}^{3}} \int_{0}^{R_{\mathrm{d}}} R^{2} T(R) \mathrm{d} R$.

\section{Results}

As mentioned in the Introduction, the comparison between experimental data and predictions of the model was performed for two cases: droplet heating and evaporation in an air flow with prescribed temperatures, and their heating and evaporation in a flame produced by combustion of the previously injected droplets. These are discussed separately in the following subsections. The measurements of the droplet velocities and the hot air temperature on the droplet axis are used as inputs in our simulations. The approximations of these parameters, used in our computations are summarised in Appendix A.

\subsection{Droplet heating and evaporation in a hot air flow}

In the first experiment, ethanol droplets with initial radii $65 \mu \mathrm{m}$, initial temperature $298.75 \mathrm{~K}$ and initial distance parameter $C=6.7$ were considered. Based on Eqs. (7)-(9) and (A.1) and (A.2), the Nusselt and Sherwood numbers were calculated. The values of droplet radii calculated at the previous time step were used to derive these numbers. Then the droplet radii and temperatures were calculated as described in Section 3.

The measured and calculated values of droplet temperature versus time elapsed from droplet injection are shown in Fig. 6. In the same figure, the time dependence of gas temperature at droplet locations is shown. The predicted values of droplet radii are not shown, as they were not measured in our experiment. As follows from this figure, temperatures at the surface and centre of the droplets, and droplet average temperatures differ considerably from one another, especially at the initial stage of droplet heating and evaporation. The best agreement with experimental data is observed for the droplet average temperatures up to $2 \mathrm{~ms}$. After $2 \mathrm{~ms}$, the model overpredicts the experimental data. The maximum droplet temperature, observed experimentally and predicted by the model, is related to a decrease in gas temperature. In this case, after about $2.5 \mathrm{~ms}$, droplet cooling due to evaporation has a greater effect than droplet heating by the surrounding gas. This effect is not related to maximum droplet temperature during the evaporation due to the contribution of thermal radiation (see $[29,30]$ for details). The model clearly overestimates the measurements in the case of ethanol droplets: the observed deviations between the experimental results and the predictions of the model can reach $4 \mathrm{~K}$ and can be attributed to a number of experimental factors, including random motions of the droplets, especially when the distance from the nozzle increases.

In the second experiment, ethanol droplets with initial radii $118.7 \mu \mathrm{m}$, initial temperature $294 \mathrm{~K}$ and initial distance parameter $C=3.97$ were considered. The time dependence of the ambient gas temperature was described by Eq. (A.4) (Note the dependencies of the ambient gas temperatures on $z$ are identical for experiments 1 and 2, but their dependencies on $t$ vary due to different droplet 


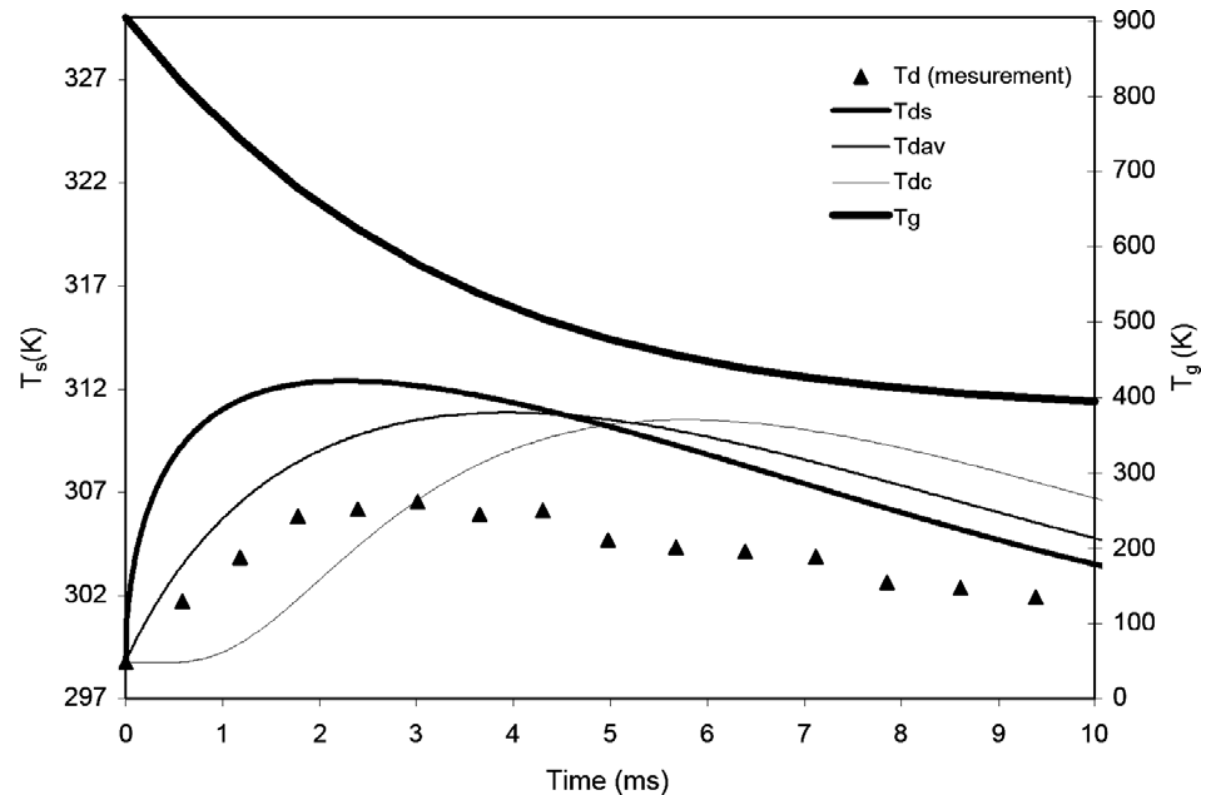

Fig. 6. Plots of ethanol droplet temperature $T_{\mathrm{d}}$, measured experimentally (solid triangles) and predicted by the model ( $T_{\mathrm{ds}}$ droplet temperatures at the surface of the droplet, $T_{\mathrm{dav}}$ average droplet temperature, and $T_{\mathrm{dc}}$ droplet temperature at the centre of the droplet) and gas temperature $T_{\mathrm{g}}$ for the initial conditions $R_{\mathrm{d} 0}=65 \mu \mathrm{m}, T_{\mathrm{d} 0}=298.75 \mathrm{~K}, C=6.72$.

velocities). The observed time dependence of droplet relative velocities has been approximated by Eq. (A.3). The Nusselt and Sherwood numbers were calculated similarly to the first experiment. The plots referring to the second experiment are shown in Fig. 7. As in the case of Fig. 6, temperatures at the surface and centre of the droplets, and droplet average temperatures differ considerably from one another, especially at the initial stage of droplet heating and evaporation. The best agreement with exper- imental data in the case shown in Figs. 5 and 7 is observed not for droplet average temperature but for the temperature between the average temperature and the temperature at the centre of the droplet. This can be related to the fact that the measurement volume in this case is noticeably less than the droplet volume. As in the case shown in Fig. 6, the maximum droplet temperature, observed experimentally and predicted by the model is related to a decrease in gas temperature. This maximum

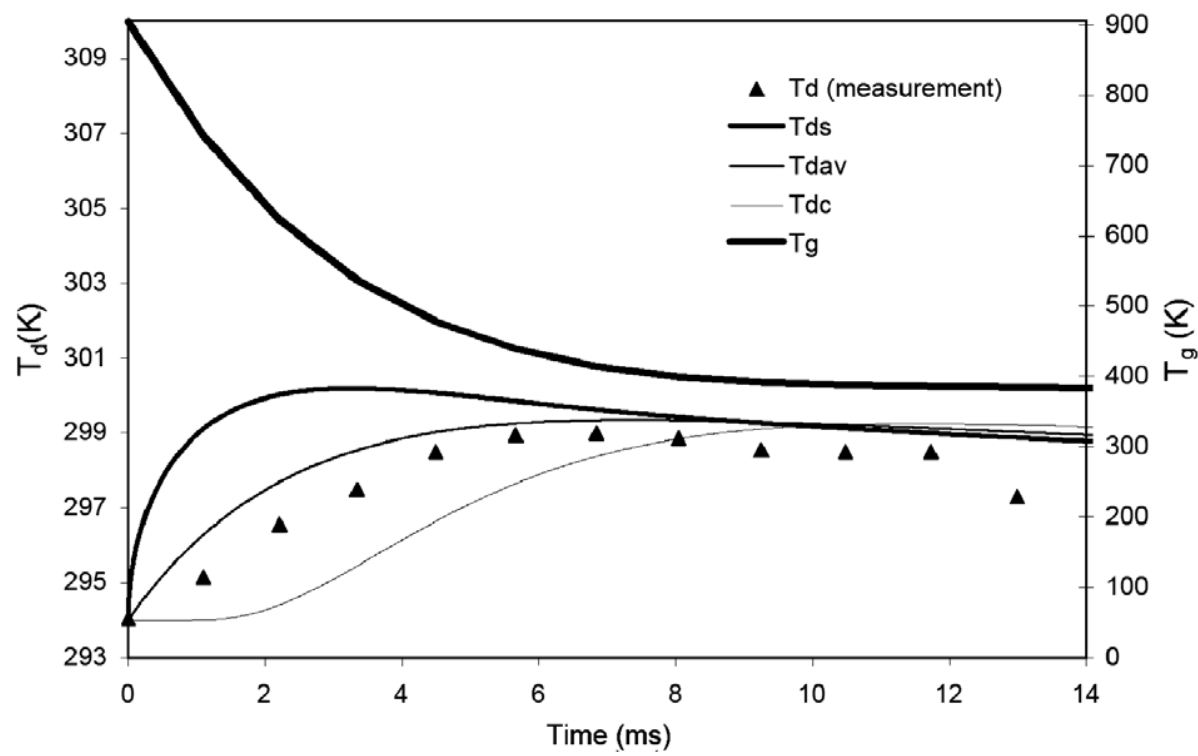

Fig. 7. Plots of ethanol droplet temperature $T_{\mathrm{d}}$, measured experimentally (solid triangles) and predicted by the model ( $T_{\mathrm{ds}}$ droplet temperatures at the surface of the droplet, $T_{\mathrm{dav}}$ average droplet temperature, and $T_{\mathrm{dc}}$ droplet temperature at the centre of the droplet) and gas temperature $T_{\mathrm{g}}$ for the initial conditions $R_{\mathrm{d} 0}=118.7 \mu \mathrm{m}, T_{\mathrm{d} 0}=294 \mathrm{~K}, C=3.97$. 
for the second experiment is observed at later times (about $6 \mathrm{~ms})$.

In the third experiment, acetone droplets with initial radii $63.2 \mu \mathrm{m}$, initial temperature $300 \mathrm{~K}$ and initial distance parameter $C=7.56$ were considered. The approximations of the observed time dependence of the droplet relative velocities and ambient gas temperature are given by Eqs. (A.5) and (A.6). In the fourth experiment, acetone droplets with initial radii $116.2 \mu \mathrm{m}$, initial temperature $296 \mathrm{~K}$ and initial distance parameter $C=3.52$ were considered (see Eqs. (A.7) and (A.8) for the time dependence of the relative droplet velocity and the ambient gas temperature). The plots are similar to those shown in Figs. 6 and 7, but for the third and fourth experiments, are shown in Figs. 8 and 9 , respectively. In contrast to the case of heating and evaporation of ethanol droplets, the initial heating of acetone droplets is hardly visible, while the temperature drop for acetone droplets is much more pronounced than is the case for ethanol droplets. This can be attributed to the higher volatility of acetone compared with ethanol. The initial heating of acetone droplets is almost completely compensated by their cooling due to evaporation. In the case shown in Fig. 8, the predicted temperatures at the centre and the surface of the droplets and the droplet average temperature proved to be rather close. In the case shown in Fig. 9, the best agreement with experimental data can be observed for the temperature at the centre of the droplets, at least at the initial stage of droplet evaporation. This was expected because the measurement volume was slightly smaller than the droplets (see Section 2.4).

\subsection{Droplet heating and evaporation inside a flame}

The experiments, focused on heating and evaporation of droplets injected into a flame produced by previously injected combusting droplets, allow us to investigate these processes over a much wider range of temperatures. Also, in these experiments, the time evolution of droplet radii was measured. The values of both droplet temperatures and radii are compared with the predictions of the model described in Section 3. In contrast to the cases considered in Section 4.1, however, only measurements of the average gas temperature at a single location of the droplets could be performed in the case of the experiments discussed in this section. The ambient temperature is assumed to be constant and its value is obtained from Fig. 5 for the given initial distance parameter $C$. As in the cases considered in Section 4.1, droplet velocities were not calculated, but measured.

In the first experiment, ethanol droplets with initial radii $52.3 \mu \mathrm{m}$, initial temperatures $309 \mathrm{~K}$ and initial distance parameter $C=3.4$ were considered. The average gas temperature at the location of the droplets was $1140 \mathrm{~K}$, and the droplet velocity evolved as described by Eq. (A.9). The measured and calculated values of droplet radii and temperature (at the centre and the surface of the droplet, and average droplet temperature) versus time are shown in Fig. 10. As in the cases shown in Figs. 6 and 8, the best agreement with experimental data at the initial stage of droplet evaporation is observed for the droplet average temperatures. The agreement between the results of

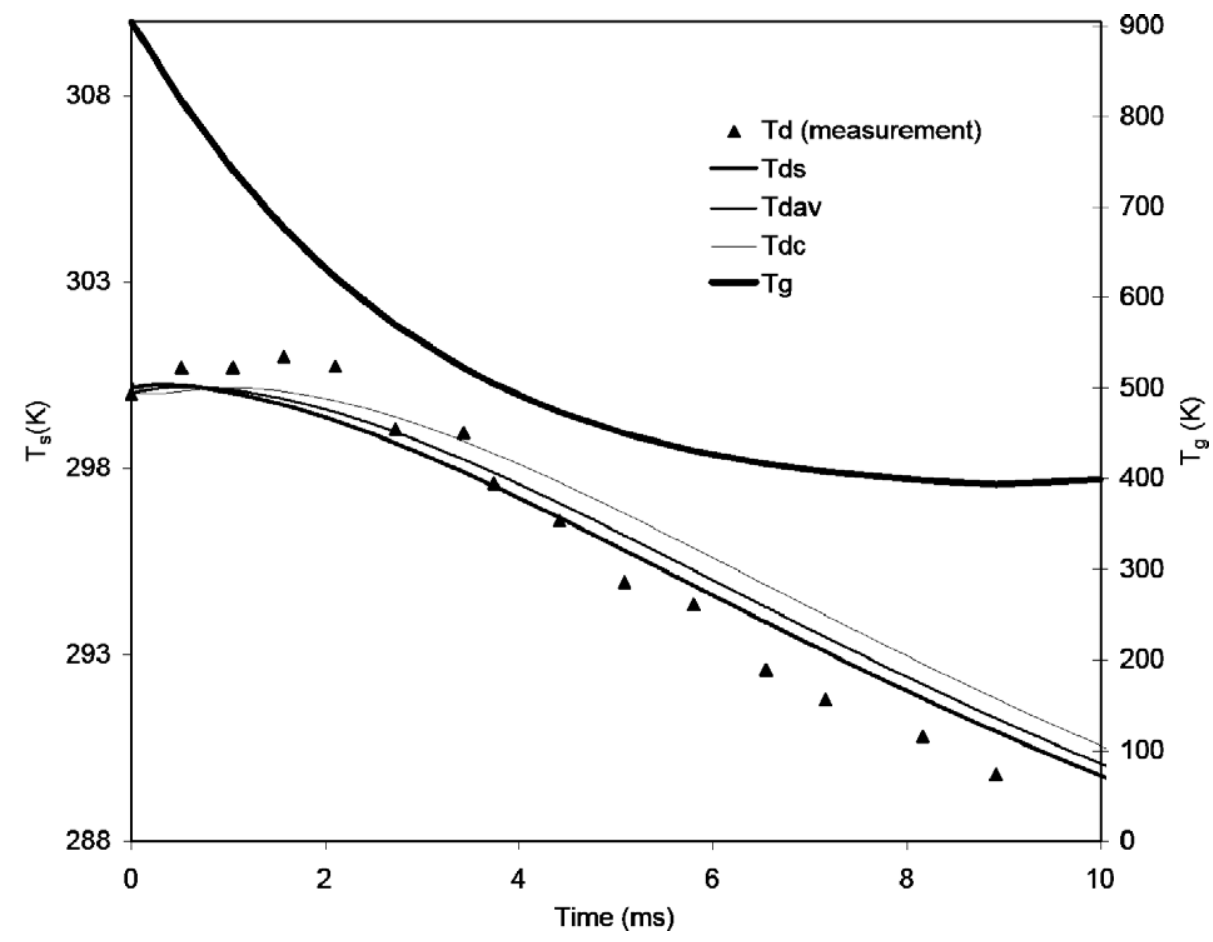

Fig. 8. Plots of acetone droplet temperature $T_{\mathrm{d}}$, measured experimentally (solid triangles) and predicted by the model ( $T_{\mathrm{ds}}$ droplet temperatures at the surface of the droplet, $T_{\mathrm{dav}}$ average droplet temperature, and $T_{\mathrm{dc}}$ droplet temperature at the centre of the droplet) and gas temperature $T_{\mathrm{g}}$ for the initial conditions $R_{\mathrm{d} 0}=63.2 \mu \mathrm{m}, T_{\mathrm{d} 0}=300 \mathrm{~K}, C=7.56$. 


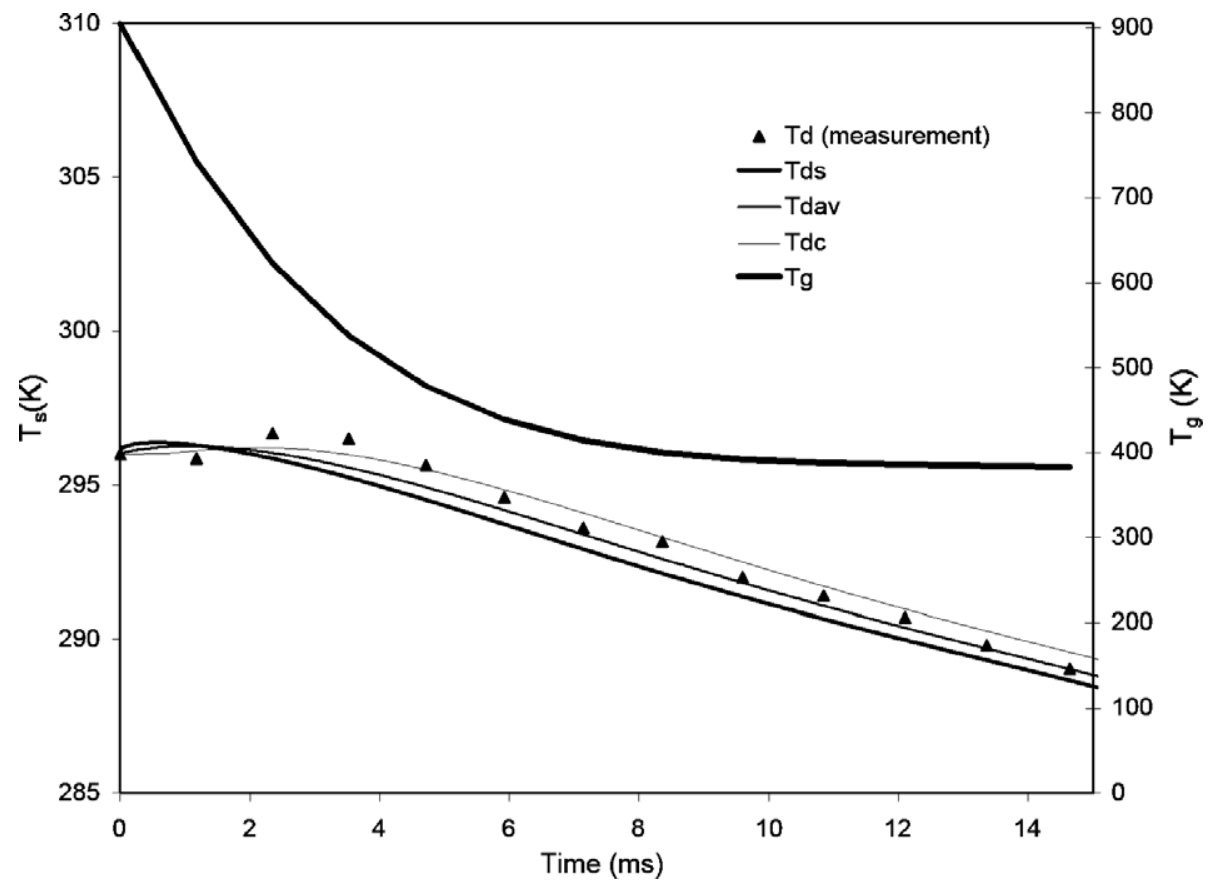

Fig. 9. Plots of acetone droplet temperature $T_{\mathrm{d}}$, measured experimentally (solid triangles) and predicted by the model ( $T_{\mathrm{ds}}$ droplet temperatures at the surface of the droplet, $T_{\mathrm{dav}}$ average droplet temperature, and $T_{\mathrm{dc}}$ droplet temperature at the centre of the droplet) and gas temperature $T_{\mathrm{g}}$ for the initial conditions $R_{\mathrm{d} 0}=116.2 \mu \mathrm{m}, T_{\mathrm{d} 0}=296 \mathrm{~K}, C=3.52$.

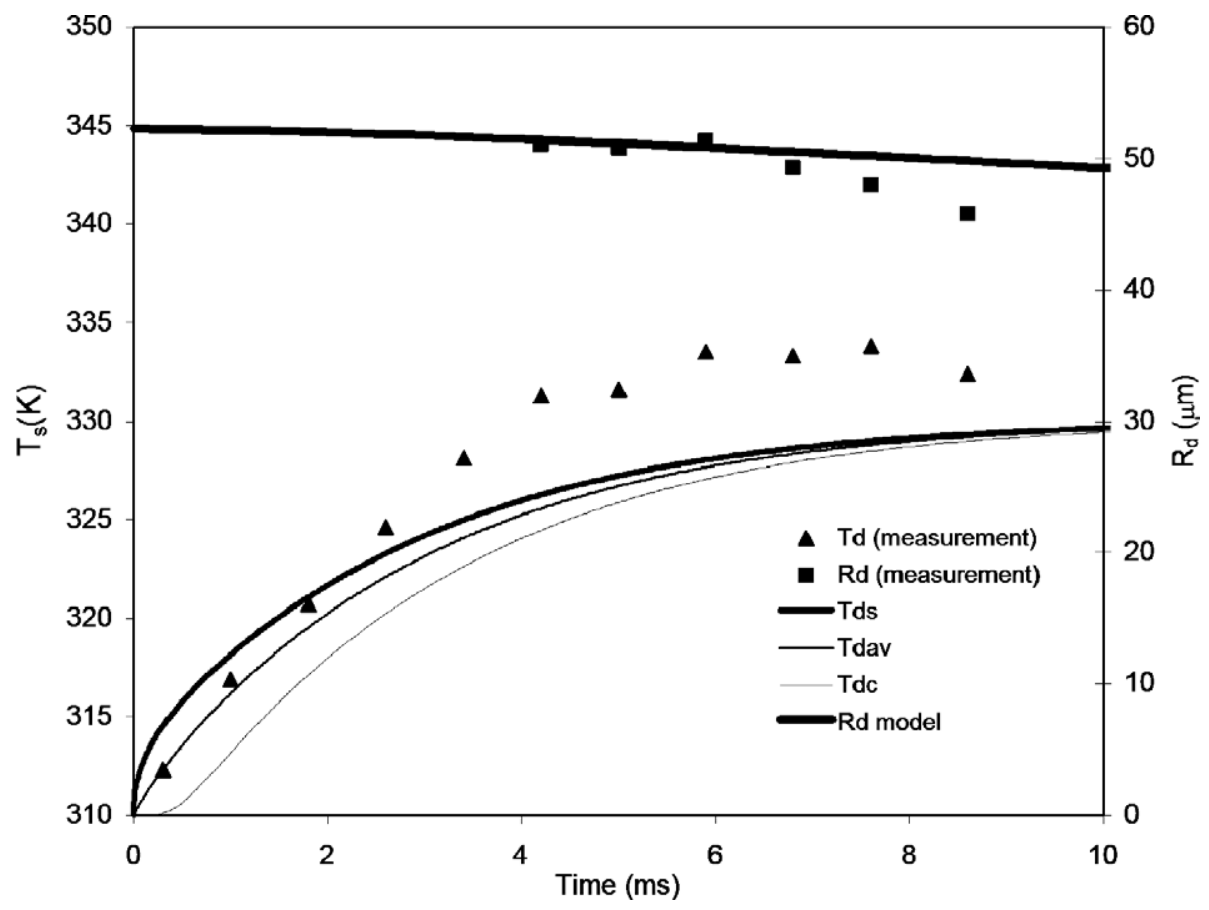

Fig. 10. Plots of ethanol droplet temperature $T_{\mathrm{d}}$ radius $R_{\mathrm{d}}$, measured experimentally (solid triangles and squares) and predicted by the model ( $T_{\mathrm{ds}}$ droplet temperatures at the surface of the droplet, $T_{\mathrm{dav}}$ average droplet temperature, and $T_{\mathrm{dc}}$ droplet temperature at the centre of the droplet) and droplet radii $R_{\mathrm{d}}$ for gas average temperature $T_{\mathrm{g}}$ equal to $1140 \mathrm{~K}$ for the initial conditions $R_{\mathrm{d} 0}=52.3 \mu \mathrm{m}, T_{\mathrm{d} 0}=309 \mathrm{~K}, C=3.4$.

modelling and experimental results both for droplet temperatures and radii seems to be reasonably good, at least at the initial stage of droplet heating and evaporation. It is however, worse in the cases shown in Fig. 10, at the later stages of droplet evaporation than in the cases considered in Section 4.1.

In the second and third experiments, ethanol droplets with the same initial radii and temperatures as in the first 


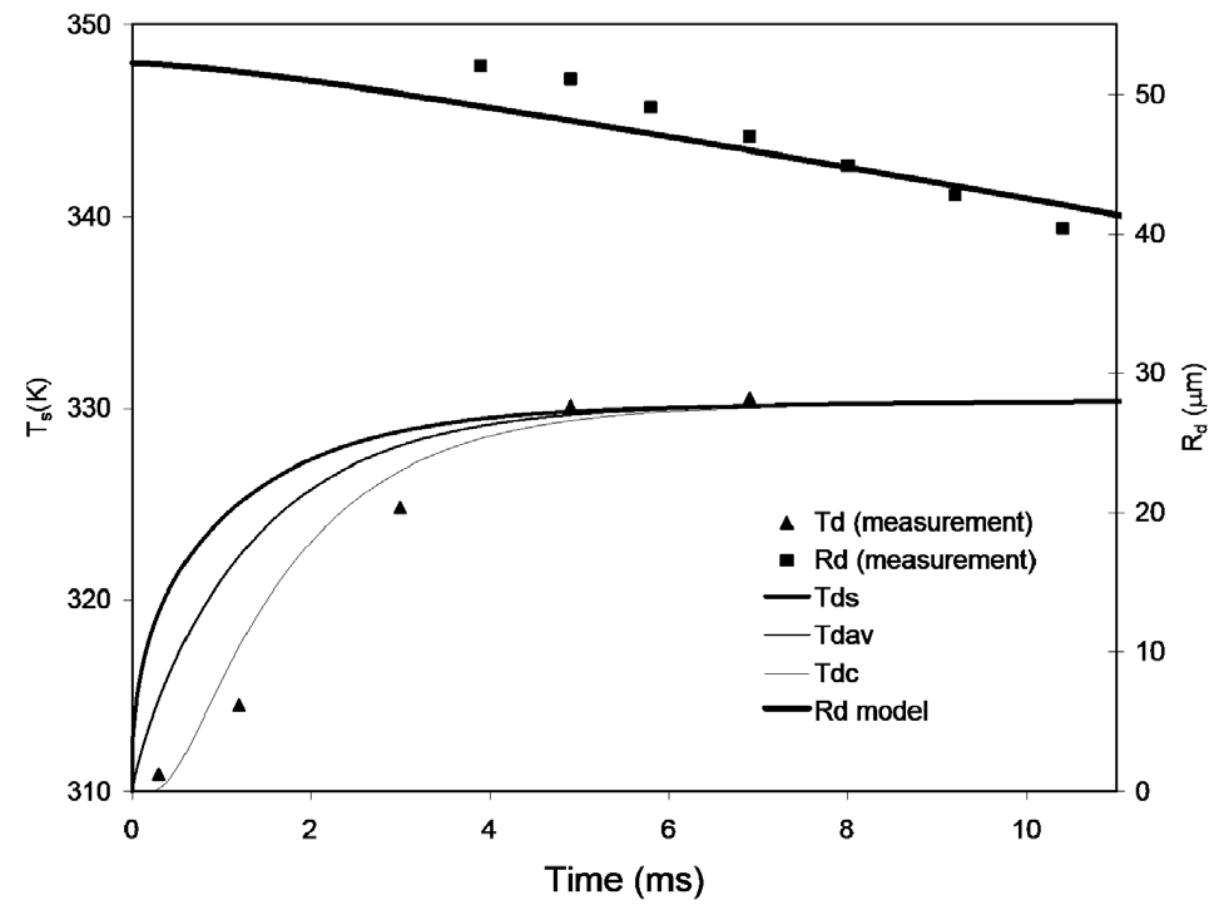

Fig. 11. Plots of ethanol droplet temperature $T_{\mathrm{d}}$ and radius $R_{\mathrm{d}}$, measured experimentally (solid triangles and squares) and predicted by the model ( $T_{\mathrm{ds}}$ droplet temperatures at the surface of the droplet, $T_{\mathrm{dav}}$ average droplet temperature, and $T_{\mathrm{dc}}$ droplet temperature at the centre of the droplet) for gas average temperature $T_{\mathrm{g}}$ equal to $1260 \mathrm{~K}$ for the initial conditions $R_{\mathrm{d} 0}=52.3 \mu \mathrm{m}, T_{\mathrm{d} 0}=309 \mathrm{~K}, C=6.0$.

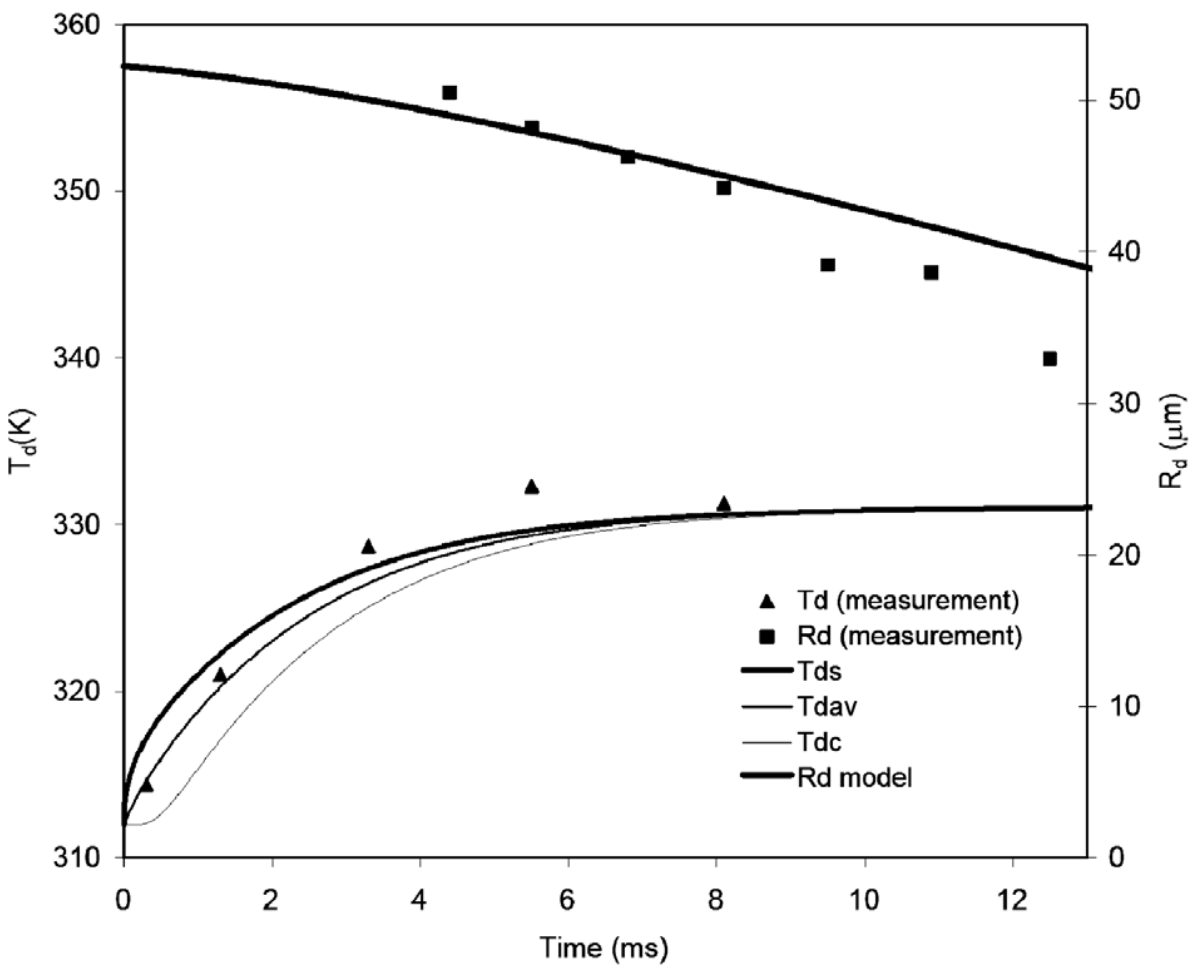

Fig. 12. Plots of ethanol droplet temperature $T_{\mathrm{d}}$ and radius $R_{\mathrm{d}}$, measured experimentally (solid triangles and squares) and predicted by the model ( $T_{\mathrm{ds}}$ droplet temperatures at the surface of the droplet, $T_{\mathrm{dav}}$ average droplet temperature, and $T_{\mathrm{dc}}$ droplet temperature at the centre of the droplet) for gas average temperature $T_{\mathrm{g}}$ equal to $1270 \mathrm{~K}$ and for the initial conditions $R_{\mathrm{d} 0}=52.3 \mu \mathrm{m}, T_{\mathrm{d} 0}=309 \mathrm{~K}, C=10.5$.

experiment, but with initial distance parameters $C=6.0$ and $C=10.5$, respectively, were considered (see Eqs.
(A.11)-(A.14) for gas temperatures and droplet velocities). The measured and calculated values of droplet radii and 
temperature (at the centre and the surface of the droplet, and average droplet temperature) versus time are shown in Figs. 11 and 12, respectively. As in the cases shown in Fig. 10, the best agreement with experimental data in the case shown in Fig. 12 at the initial stage of droplet heating and evaporation is observed for the droplet average temperatures. In the case shown in Fig. 11, the best agreement is observed for the temperature at the centre of the droplet. The reason for this is not clear to us.

\section{Conclusions}

Heating and evaporation of monodisperse ethanol and acetone droplets has been studied in two regimes: pure heating and evaporation of droplets in a flow of air of prescribed temperature, and droplet heating and evaporation in a flame produced by previously injected combusting droplets. Two-colour laser induced fluorescence thermometry has been used for the estimate of droplet temperatures, while their sizes and velocities have been characterized by phase Doppler anemometry. In the flames, CARS technique made it possible to estimate the gas temperature. The experiments have been performed for various distances between droplets and various initial droplet radii and velocities. The experimental data have been compared with the results of modelling, based on given gas temperatures, and Nusselt and Sherwood numbers calculated using measured values of droplet relative velocities. When estimating the latter numbers the finite distance between droplets has been taken into account. The model has been based on the assumption that droplets are spherically symmetric with a radial distribution of temperature inside them taken into account. This model considers recirculation inside droplets via the introduction of the effective thermal conductivity of droplets (effective thermal conductivity model). In the gas phase, it takes into account the effect of finite thickness of the thermal boundary layer around droplets. The radiative heating of droplets has been calculated taking into account the semitransparency of droplets. The radiative effects, however, have been shown to be small and were ignored in most of the analysis. It has been pointed out that for relatively small droplets (initial radii about $65 \mu \mathrm{m}$ ) the experimentally measured droplet temperatures are close to the predicted average droplet temperatures, while they are closer to the temperatures predicted at the centre of the droplets when the droplet diameter is larger than the probe volume size of the two-colour LIF thermometry. The presented model has been validated for different configurations ranging from solely evaporating droplets to evaporating and combusting droplets. Throughout this study, the distance parameter (ratio of the distance between droplets to their diameters) has been extended from 3 to almost 11 without any significant worsening of the prediction accuracy. This has given us some levels of reliability for the way in which droplet-to-droplet interactions are taken into account.

\section{Acknowledgements}

Two of the co-authors (TK and SSS) are grateful to the European Regional Development Fund Franco-British INTERREG IIIa (Project Ref. 162/025/247) and the Indonesian Government (TPSDP, Batch III) for financial support for their part of the work on this paper. Four of the co-authors (CM, GC, FG and FL) are grateful to CNRS and ONERA for their financial support of the ASTRA program. Our special thanks go to Dr. W Abdelghaffar, who developed the original version of the program used for the modelling of the processes discussed in this paper, and Dr. S Martynov for useful discussions.

\section{Appendix A. Relative droplet velocities and gas temperatures used in the simulations}

\section{A.1. Droplet heating and evaporation in a hot air flow}

First experiment: Ethanol droplets $\left(R_{\mathrm{d} 0}=65 \mu \mathrm{m}, T_{\mathrm{d} 0}=\right.$ $298.75 \mathrm{~K}, C=6.72$ )

$v_{\mathrm{d}}(t)=0.0024 t^{3}-0.0268 t^{2}-0.1940 t+8.5744$

$T\left({ }^{\circ} \mathrm{C}\right)=0.0361 t^{4}-1.3536 t^{3}+20.905 t^{2}-160.6 t+631.62$

Second experiment: Ethanol droplets $\left(R_{\mathrm{d} 0}=118.7 \mu \mathrm{m}\right.$, $\left.T_{\mathrm{d} 0}=294 \mathrm{~K}, C=3.97\right)$

$v_{\mathrm{d}}(t)=0.00294 t^{2}-0.1383 t+9.154$

$T\left({ }^{\circ} \mathrm{C}\right)=0.0264 t^{4}-1.2121 t^{3}+21.113 t^{2}-167.75 t+630.86$

Third experiment: Acetone droplets $\left(R_{\mathrm{d} 0}=63.2 \mu \mathrm{m}\right.$, $\left.T_{\mathrm{d} 0}=300 \mathrm{~K}, C=7.56\right)$

$v_{\mathrm{d}}(t)=0.0004701 t^{3}-0.014067 t^{2}-0.18347 t+9.7742(\mathrm{~A} .5)$

$T\left({ }^{\circ} \mathrm{C}\right)=0.0597 t^{4}-1.9605 t^{3}+26.634 t^{2}-180.4 t+631.08$

Fourth experiment: Acetone droplets $\left(R_{\mathrm{d} 0}=116.2 \mu \mathrm{m}\right.$, $\left.T_{\mathrm{d} 0}=296 \mathrm{~K}, C=3.52\right)$

$v_{\mathrm{d}}(t)=0.0001461 t^{2}-0.05631 t+8.561$.

$T\left({ }^{\circ} \mathrm{C}\right)=0.0207 t^{4}-1.0108 t^{3}+18.779 t^{2}-158.7 t+631$.

\section{A.2. Droplet heating and evaporation inside a flame}

First experiment: Ethanol droplets $\left(R_{\mathrm{d} 0}=52.3 \mu \mathrm{m}\right.$, $\left.T_{\mathrm{d} 0}=309 \mathrm{~K}, C=3.4\right)$

$v_{\mathrm{d}}(t)=-0.0021 t^{3}+0.0332 t^{2}-0.3221 t+6.9956$

$T=1140 \mathrm{~K}$

Second experiment: Ethanol droplets $\left(R_{\mathrm{d} 0}=52.3 \mu \mathrm{m}\right.$, $T_{\mathrm{d} 0}=309 \mathrm{~K}, C=6.0$ ) 


$$
v_{\mathrm{d}}(t)=-0.0052 t^{3}+0.0943 t^{2}-0.7238 t+6.9138
$$

$T=1260 \mathrm{~K}$

Third experiment: Ethanol droplets $\left(R_{\mathrm{d} 0}=52.3 \mu \mathrm{m}\right.$, $T_{\mathrm{d} 0}=309 \mathrm{~K}, C=10.5$ )

$v_{\mathrm{d}}(t)=0.005 t^{3}+0.1145 t^{2}-0.9830 t+6.8877$

$T=1270 \mathrm{~K}$

Note that $v_{\mathrm{d}}$ corresponds to the relative velocity (difference between the absolute velocity of the droplets and the velocity of the air stream), $t$ is in milliseconds, $v_{\mathrm{d}}$ is in $\mathrm{m} / \mathrm{s}$.

\section{References}

[1] W.A. Sirignano, Fluid Dynamics and Transport of Droplets and Sprays, Cambridge University Press, 1999.

[2] B. Abramzon, W.A. Sirignano, Droplet vaporization model for spray combustion calculations, Int. J. Heat Mass Transfer 32 (1989) 16051618.

[3] E.E. Michaelides, Hydrodynamic force and heat/mass transfer from particles, bubbles, and drops - the Freeman scholar lecture, ASME J Fluid Eng. 125 (2003) 209-238.

[4] S.S. Sazhin, Advanced models of fuel droplet heating and evaporation, Prog. Energy Combust. Sci. 32 (2006) 162-214.

[5] H.A. Dwyer, P. Stapf, R. Maly, Unsteady vaporization and ignition of a three-dimensional droplet array, Combust. Flame 121 (2000) $181-194$.

[6] K. Harstad, J. Bellan, Evaluation of commonly used assumptions for isolated and cluster heptane drops in nitrogen at all pressures, Combust. Flame 127 (2001) 1861-1879.

[7] A. Frohn, N. Roth, Dynamics of Droplets, Springer-Verlag, Berlin and Heidelberg $\mathrm{GmbH}, 2000$.

[8] J.J. Sangiovanni, A.S. Kesten, Effect of droplet interaction on ignition in monodispersed droplet streams, in: Sixteenth International Symposium on Combustion, The Combustion Institute, 1976.

[9] J.J. Sangiovanni, M. Labowski, Burning times of linear fuel droplet arrays: a comparison of experiment and theory, Combust. Flame 45 (1982) 15-30.

[10] T.A. Brzustowski, E.M. Twardus, S. Wojcicki, A. Sobiesiak, Interaction of two burning fuel droplets of arbitrary size, AIAA J. 17 (1979) 1234-1242.

[11] M. Labowsky, Calculation of the burning rates of interacting fuel droplets, Combust. Sci. Technol. 22 (1980) 217-226.

[12] M. Marberry, A.K. Ray, K. Leung, Effect of multiple particle interactions on burning droplets, Combust. Flame 57 (1984) 237-245.

[13] C.H. Chiang, W.A. Sirignano, Interacting, convecting, vaporizing fuel droplets with variable properties, Int. J. Heat Mass Transfer 36 (1993) 875-886.

[14] C.H. Chiang, W.A. Sirignano, Axisymmetric calculations of three droplet interactions, Atomization Sprays 3 (1993) 91-107.
[15] G. Castanet, P. Lavieille, F. Lemoine, M. Lebouché, A. Atthasit, Y. Biscos, G. Lavergne, Energetic budget on an evaporating monodisperse droplet stream using combined optical methods. Evaluation of the convective heat transfer, Int. J. Heat Mass Transfer 45 (2002) 5053-5067.

[16] G. Castanet, M. Lebouché, F. Lemoine, Heat and mass transfer of combusting monodisperse droplets in a linear stream, Int. J. Heat Mass Transfer 48 (2005) 3261-3275.

[17] C. Maqua, G. Castanet, N. Doué, G. Lavergne, F. Lemoine, Temperature measurements of binary droplets using three color laser-induced fluorescence, Exp. Fluid 40 (2006) 786-797.

[18] S. Druet, J.P. Taran, CARS Spectroscopy, Prog. Quant. Electr. 7 (1) (1981) 1-72.

[19] S.S. Sazhin, P.A. Krutitskii, W.A. Abdelghaffar, E.M. Sazhina, S.V. Mikhalovsky, S.T. Meikle, M.R. Heikal, Transient heating of diesel fuel droplets, Int. J. Heat Mass Transfer 47 (2004) 3327-3340.

[20] S.S. Sazhin, W.A. Abdelghaffar, P.A. Krutitskii, E.M. Sazhina, M.R. Heikal, New approaches to numerical modelling of droplet transient heating and evaporation, Int. J. Heat Mass Transfer 48 (2005) 42154228 .

[21] S.S. Sazhin, T. Kristyadi, W.A. Abdelghaffar, M.R. Heikal, Models for fuel droplet heating and evaporation: comparative analysis, Fuel 85 (12-13) (2006) 1613-1630.

[22] C. Maqua, G. Castanet, F. Lemoine, Temperature measurements of binary evaporating droplets using three colour laser induced fluorescence, in: 13th International Heat Transfer conference, Sydney, Australia, 2006.

[23] A.C. Eckbreth, Laser Diagnostics for Combustion Temperature and Species, Second ed., Gordon and Breach, Amsterdam, 1996.

[24] F. Grisch, P. Bouchardy, L. Vingert, W. Clauss, M. Oschwald, O.M. Stel'mack, V.V. Smirnov, Coherent anti-stokes Raman scattering measurements at high pressure in cryogenic $\mathrm{LOX} / \mathrm{GH}_{2}$ Jet flames, in liquid rocket thrust chambers: aspects of modeling, analysis and design, Prog. Astronaut. Aeronaut. 200 (10) (2004) 369-404.

[25] J. Bonamy, L. Bonamy, D. Robert, Overlapping effects and motional narrowing in molecular band shapes - Application to Q-branch of HD, J. Chem. Phys. 67 (10) (1977) 4441-4453.

[26] P. Lavieille, F. Lemoine, G. Lavergne, M. Lebouché, Evaporating and combusting droplet temperature measurements using two color laser induced fluorescence, Exp. Fluids 31 (2001) 45-55.

[27] P. Lavieille, F. Lemoine, M. Lebouché, Investigation on temperature of evaporating droplets in a linear stream using two color laser induced fluorescence, Combust. Sci. Technol. 174 (2002) 117-142.

[28] S.S. Sazhin, P.A. Krutitskii, A conduction model for transient heating of fuel droplets, in: H.G.W. Begehre, R.P. MGilbert, W. Wong (Eds.), Progress in Analysis vol. II, Proceedings of the Third International ISAAC Congress, (August 20-25, 2001, Berlin), World Scientific, Singapore, 2003, pp. 1231-1239.

[29] B. Abramzon, S. Sazhin, Droplet vaporization model in the presence of thermal radiation, Int. J. Heat Mass Transfer 48 (2005) 1868-1873.

[30] B. Abramzon, S. Sazhin, Convective vaporization of fuel droplets with thermal radiation absorption, Fuel 85 (1) (2006) 32-46. 